\title{
Recent updates in mechanical ventilation
} Valentina Bergamaschi and Paolo Navalesi*

\author{
Address: Università degli Studi del Piemonte Orientale 'A Avogadro', SCDU Anestesia, Terapia Intensiva e Rianimazione Generale, Azienda \\ Ospedaliera Universitaria 'Maggiore della Carità', C.so Mazzini 18, 28100 Novara, Italy \\ *Corresponding author: Paolo Navalesi (paolo.navalesi@med.unipmn.it) \\ FI000 Medicine Reports 2009, I:I2 (doi: 10.34I0/MI-I2)
}

The electronic version of this article is the complete one and can be found at: http://FI000.com/Reports/Medicine/content/I/I2

\begin{abstract}
Recently, several studies have been performed to better outline the pathophysiology of acute respiratory failure and evaluate the therapeutic profile of different modes of ventilation and ventilator settings. Here we briefly report those we consider most relevant for daily intensive care unit clinical practice.
\end{abstract}

\section{Introduction and context}

The optimization of ventilatory support is a crucial issue in the management of patients with acute respiratory failure, aiming at improving gas exchange and patient-ventilator interaction while preventing ventilator-induced dysfunction of the respiratory system.

\section{Recent advances}

A very important study by Levine et al. [1] shows in humans, as previously observed in animal models, that the combination of diaphragm inactivity and mechanical ventilation is associated with marked diaphragm atrophy. Diaphragm atrophy, which may occur after just 18 hours of controlled mechanical ventilation as a result of increased myofibril proteolysis, may contribute to prolongation and/or failure of the weaning process. This study, performed in brain-dead organ donors, underlines the importance of using modes of partial ventilatory support whenever possible and not contraindicated, in order to reduce the time spent on mechanical ventilation and its side effects.

Relevant clinical research has investigated the complex interaction between patient and ventilator during partial support. Thille et al. [2] compared three different strategies conventionally aimed to optimize patientventilator interaction in pressure support ventilation (PSV): reduction of support level, reduction of insufflation time and application of positive end-expiratory pressure (PEEP). The reduction of pressure support succeeded in eliminating ineffective triggering in twothirds of the patients without increasing the work of the respiratory muscles or altering gas exchange, while the effects of reducing insufflation time and increasing PEEP were less important and not significant. The improvement in patient-ventilator synchrony becomes relevant when tidal volume $\left(\mathrm{V}_{\mathrm{T}}\right)$ is reduced to $6 \mathrm{ml} / \mathrm{kg}$, which is therefore suggested by the authors as a target for adjustment of inspiratory pressure support level.

Neurally adjusted ventilatory assist (NAVA) is a new form of partial support wherein the ventilator applies positive pressure throughout inspiration in proportion to the electrical activity of the diaphragm, as assessed by transoesophageal electromyography. Allowing ventilator functioning and cycling to be under direct control of the patient's respiratory drive and rhythm, NAVA aims to enhance patient-ventilator interaction and minimize the risk of over-assistance. A recent study by Colombo et al. [3] compares the physiological response to different levels of assistance delivered with NAVA and PSV. As opposed to NAVA, PSV was prone to the risk of over-assistance, as identified by higher $V_{T}$, significant mismatch between neural and flow-based timing and frequent occurrence of ineffective efforts. The study indicates that, compared to PSV, NAVA has the potential to limit the risk of over-assistance, prevent 
patient-ventilator asynchrony, and, overall, improve patient-ventilator interaction.

Two recent trials have evaluated the impact of different ventilator settings in the prevention of ventilatorinduced lung injury (VILI) in patients with acute lung injury and acute respiratory distress syndrome (ARDS).

Meade et al. [4] compared the effects of a ventilatory strategy combining low $\mathrm{V}_{\mathrm{T}}$, recruitment manoeuvres and high levels of PEEP with the established ventilatory strategy. In the experimental group, $\mathrm{V}_{\mathrm{T}}$ was set at $6 \mathrm{ml} / \mathrm{kg}$, with plateau airway pressures $\left(\mathrm{P}_{\text {aw-plateau }}\right)<40 \mathrm{cmH}_{2} \mathrm{O}$. Each trial started with a 40-second breath-hold at $40 \mathrm{cmH}_{2} \mathrm{O} \mathrm{P}_{\mathrm{aw}}$ recruitment manoeuvre on a fraction of inspired oxygen $\left(\mathrm{FiO}_{2}\right)$ of 1.0, which could be repeated up to four times daily. The control group underwent the ARDS Network ventilation protocol (volume-assist control mode, $\mathrm{V}_{\mathrm{T}} 6 \mathrm{ml} / \mathrm{kg}$ and $\mathrm{P}_{\text {aw-plateau }}<30 \mathrm{cmH}_{2} \mathrm{O}$, with PEEP determined according to $\mathrm{FiO}_{2}$, no recruitment manoeuvre). Results showed a significant difference in PEEP levels associated with lower incidence of hypoxemia and $\mathrm{FiO}_{2}$ requirement, less recourse to rescue oxygenation therapies, and fewer deaths due to refractory hypoxemia in the intervention group, as opposed to the control group, while no significant difference in mortality rate and duration of mechanical ventilation was found.

Mercat et al. [5] evaluated a strategy using high PEEP levels to increase alveolar recruitment while avoiding excessive hyperinflation by limiting $\mathrm{P}_{\text {aw-plateau }}$ and using low $\mathrm{V}_{\mathrm{T}}$. In the control group, $\mathrm{P}_{\text {aw-plateau }}$ was kept as low as possible without falling below oxygenation targets, setting PEEP between 5 and $9 \mathrm{cmH}_{2} \mathrm{O}$. In the experimental group, PEEP was adjusted based on $\mathrm{P}_{\mathrm{aw}}$ and kept as high as possible without increasing $\mathrm{P}_{\text {aw-plateau }}$ above $28-30 \mathrm{~cm} \mathrm{H}_{2} \mathrm{O}$, regardless of its effects on oxygenation. The experimental strategy significantly improved oxygenation and respiratory system compliance and reduced the time spent on mechanical ventilation and with organ failures, but failed to reduce mortality.

In an intriguing study, Chiumello et al. [6] consider VILI a result of excessive lung stress and strain, as assessed by transpulmonary pressure and inflated volume to functional residual capacity ratio, respectively. As stress and strain cannot be measured in clinical practice, the study aims to determine the accuracy at which the two parameters can be inferred by analyzing their commonly utilized surrogates, that is, $\mathrm{P}_{\text {aw-plateau }}$ and $\mathrm{V}_{\mathrm{T}} / \mathrm{kg}$. Currently, prevention of VILI is based on recognizing the harmful threshold for these surrogates, identified as 28-30 $\mathrm{cmH}_{2} \mathrm{O}\left(\mathrm{P}_{\text {aw-plateau }}\right)$ and $6 \mathrm{ml} / \mathrm{kg}\left(\mathrm{V}_{\mathrm{T}} / \mathrm{kg}\right)$. In a varied population ranging from postoperative patients with intact lung function to patients with ARDS, $\mathrm{P}_{\mathrm{aw} \text {-plateau }}$ and $\mathrm{V}_{\mathrm{T}}$ did not prove to be adequate surrogates for lung stress and strain. Interestingly, the stress to strain relationship was the same in all the subgroups, being linear in the ranges of pressures and volumes explored. The specific lung elastance was also similar in the various subgroups, remaining constant at approximately $13.5 \mathrm{cmH}_{2} \mathrm{O}$, regardless of ventilator settings. Because stress and strain were demonstrated to be linked by a constant proportionality factor, that is, the specific lung elastance, stress can be calculated as $13.5 \mathrm{cmH}_{2} \mathrm{O} \times$ strain. As a strain greater than 2, corresponding to an end-inspiratory lung volume in the range of total lung capacity, has been identified as critical for the risk of development of lung injury, the harmful threshold of stress will consequently be $2 \times 13.5 \mathrm{cmH}_{2} \mathrm{O}$; therefore the recommended $\mathrm{P}_{\text {aw-plateau }}$ threshold of $28-30 \mathrm{cmH}_{2} \mathrm{O}$ seems reasonable for most acute lung injury/ARDS patients.

\section{Implications for clinical practice}

The identification of diaphragmatic atrophy after just 18 hours of controlled mechanical ventilation suggests the importance of adopting modes of partial ventilatory support as soon as possible. The optimization of patientventilator synchrony should be based either on the reduction of the assistance provided with the commonly used modes of partial support or on the application of new forms of mechanical assistance designed to improve the interaction between the patient and the ventilator, such as NAVA.

In patients with ARDS, ventilatory strategies for optimizing PEEP with the aim of increasing alveolar recruitment while limiting hyperinflation succeeded in improving lung function and reducing the duration of mechanical ventilation, but failed to reduce mortality. The introduction of the measurement of lung stress and strain into daily clinical practice could allow a better identification of the safe limits of mechanical ventilation in the presence of lung injury.

\section{Abbreviations}

ARDS, acute respiratory distress syndrome; $\mathrm{FiO}_{2}$, fraction of inspired oxygen; NAVA, neurally adjusted ventilatory assist; $\mathrm{P}_{\mathrm{aw}}$, airway pressure; $\mathrm{P}_{\mathrm{aw} \text {-plateau, plateau airway }}$ pressure; PEEP, positive end-expiratory pressure; PSV, pressure support ventilation; VILI, ventilator-induced lung injury; $\mathrm{V}_{\mathrm{T}}$, tidal volume.

\section{Competing interests}

Our institution received an ICU ventilator with NAVA software, a portable PC, and dedicated data acquisition 
software from Maquet Critical Care, used in the study conducted by Colombo et al. [3].

\section{References}

I. Levine S, Nguyen T, Taylor N, Friscia ME, Budak MT, Rothenberg P, Zhu J, Sachdeva R, Sonnad S, Kaiser LR, Rubinstein NA, Powers SK, Shrager JB: Rapid disuse atrophy of diaphragm fibers in mechanically ventilated humans. N Engl J Med 2008, 358: 1327-35.

Changes Clinical Practice

FI000 Factor 8.8 Exceptional

Evaluated by Marc De Kock with Patrice Forget 2 Apr 2008, Marcelo Gama de Abreu 4 Apr 2008, Christer Sinderby 7 Apr 2008, Harald Groeben 2I Apr 2008, Rob Basner 23 Apr 2008, Naoto Morimura 21 May 2008, Antoni Torres with Jacobo Sellarés 27 May 2008

2. Thille AW, Cabello B, Galia F, Lyazidi A, Brochard L: Reduction of patient-ventilator asynchrony by reducing tidal volume during pressure-support ventilation. Intensive Care Med 2008, 34:1477-86.

FI000 Factor 3.2 Recommended

Evaluated by Christer Sinderby 20 Jun 2008, Enrico Calzia 29 Sep 2008

3. Colombo D, Cammarota G, Bergamaschi V, De Lucia M, Corte FD, Navalesi P: Physiologic response to varying levels of pressure support and neurally adjusted ventilatory assist in patients with acute respiratory failure. Intensive Care Med 2008, 34:2010-8.
4. Meade MO, Cook DJ, Guyatt GH, Slutsky AS, Arabi YM, Cooper DJ, Davies AR, Hand LE, Zhou Q, Thabane L, Austin P, Lapinsky S, Baxter A, Russell J, Skrobik Y, Ronco JJ, Stewart TE; Lung Open Ventilation Study Investigators: Ventilation strategy using low tidal volumes, recruitment maneuvers, and high positive end-expiratory pressure for acute lung injury and acute respiratory distress syndrome: a randomized controlled trial. JAMA 2008, 299:637-45.

FI000 Factor 6.6 Must Read

Evaluated by Mark Nunnally 28 Feb 2008, Jesus Villar 4 Mar 2008, Ola Stenqvist 6 Mar 2008

5. Mercat A, Richard JC, Vielle B, Jaber S, Osman D, Diehl JL, Lefrant JY Prat G, Richecoeur J, Nieszkowska A, Gervais C, Baudot J, Bouadma L, Brochard L; Expiratory Pressure (Express) Study Group: Positive end-expiratory pressure setting in adults with acute lung injury and acute respiratory distress syndrome: a randomized controlled trial. JAMA 2008, 299:646-55.

FI000 Factor 6.5 Must Read

Evaluated by John Kress with David R Brush 12 Mar 2008, Claude Guerin 26 Mar 2008, Jacob Sznajder with Manu Jain I4 May 2008

6. Chiumello $D$, Carlesso $E$, Cadringher $P$, Caironi $P$, Valenza F, Polli $F$, Tallarini F, Cozzi P, Cressoni M, Colombo A, Marini JJ, Gattinoni L: Lung stress and strain during mechanical ventilation for acute respiratory distress syndrome. Am J Respir Crit Care Med 2008, I78:346-55.

FI000 Factor 3.0 Recommended

Evaluated by Nigel Webster 26 Aug 2008 